\title{
Preparation and Properties of the Composite Enhancement Layer of Bearing Ring
}

\author{
Xiaochu Liu ${ }^{1,2,3}$, Jianfeng Huang1,2,3, Zhongwei Liang1,2,3, Weifeng Huang1,2,3, Rui Zhu 1,2,3, \\ Weilin Gao ${ }^{1,2,3}$, Jinrui Xiao ${ }^{1,2,3 *}$ \\ ${ }^{1}$ School of Mechanical and Electrical Engineering, Guangzhou University, Guangzhou, China \\ ${ }^{2}$ Guangzhou Key Laboratory of High-Performance Metal Grinding Processing, Guangzhou, China \\ ${ }^{3}$ Research Center of High-Performance Micro-Nano Machining Engineering Technology of Strengthened Grinding in Guangdong \\ Province, Guangzhou, China \\ Email: *xjr640@163.com
}

How to cite this paper: Liu, X.C., Huang, J.F., Liang, Z.W., Huang, W.F., Zhu, R., Gao, W.L. and Xiao, J.R. (2020) Preparation and Properties of the Composite Enhancement Layer of Bearing Ring. World Journal of Mechanics, 10, 139-153. https://doi.org/10.4236/wjm.2020.1010010

Received: August 17, 2020

Accepted: September 19, 2020

Published: September 22, 2020

Copyright $\odot 2020$ by author(s) and Scientific Research Publishing Inc. This work is licensed under the Creative Commons Attribution International License (CC BY 4.0).

http://creativecommons.org/licenses/by/4.0/

\begin{abstract}
In this paper, the NU308 bearing rings were subjected to strengthen grinding treatment (SGT) at ambient temperature. And the running reliabilities of specimens that subjected to SGT and conventional treatment (CT) were respectively investigated by testing dynamic properties including the running temperature, vibrations, and surface burning. Moreover, the residual stress, microtopography, and microstructures on the cross-section were respectively tested with residual stress analyzer and field-emission scanning electron microscopy. The results showed that the running reliabilities of the specimen after SGT had been significantly improved with the reduction of running temperature, vibration, and surface burning. Further study showed that the specimen's surface was filled with disordered micropores after SGT compared to the regular strip texture on the CT specimen's surface, and the maximum residual compressive stress induced by SGT was about $-900 \mathrm{MPa}$. Moreover, the thickness of the residual compressive stress layer was over $180 \mu \mathrm{m}$, while the thickness of severe plastic deformation layer was about $50 \mu \mathrm{m}$.
\end{abstract}

\section{Keywords}

Strengthen Grinding Treatment, Conventional Treatment, Composite Enhancement Layer, Running Reliability

\section{Introduction}

Bearing is one of the most widely used parts in mechanical transmission. The operational reliability of bearing ring is one of the most important properties of 
bearings. The operating reliability of the bearing is affected by many factors, which are related to the surface quality, material properties, operating conditions, the load and so on. With the development of industry, the strength of metal materials increases, but the plasticity, toughness and fatigue resistance tend to decrease. In practical applications, the failure of materials mainly occurs on the surface or subsurface, which directly affects the service life of components. Therefore, improving the surface quality of parts is a central issue in recent research. Accordingly, surface treatments on the bearing ring are proposed to boost sliding and rolling wear resistance. In recent years, surface strengthening techniques such as surface plating, surface coating, laser impact processing, shot peening, and strengthening grinding have emerged to improve the reliability of mechanical workpieces, especially bearing rings. Poor adhesion between molecules and poor chemical compatibility may cause adhesion and delamination of coatings and coatings by surface plating ref. [1] [2]. Schuhler et al. ref. [1] revealed nitriding results in higher wear resistance especially in lubricated condition. Reza Gheisari ref. [2] proved that combined effect of surface topography and hardness on the tribological performance of the coatings. While laser shock processing may enhance the tribological performance by inducing surface topography, residual compressive stress, and dense dislocation ref. [3] [4]. The laser shock process might induce plastic deformation, microhardness enhancement, and residual stress enhancement ref. [5] [6] [7] [8]. Spadaro ref. [5], Wang ref. [6], and Zhao ref. [7] certified the improvement of fatigue life reached for SP is mainly due to large amounts of twins and high residual compressive stress. Klotz ref. [8] considered the peening parameters are crucial. In low cycle fatigue, the roughness is to be considered. It is the presence of residual stress while in high cycle fatigue. Generally, shot peening is considered to be an important means to improve the fatigue resistance of metals by introducing residual compressive stress, nanocrystals, deformed twins and strain hardening ref. [9] [10]. Laser shock treatment creates surface topography and low residual compressive stress, while shot peening treatment creates high residual compressive stress. In contrast, the strengthening grinding treatment (SGT) can create both the micro-topography and high residual compressive stress, which is considered to be particularly beneficial for improving the fatigue resistance of metal components ref. [11] [12], especially for rotating parts such as bearing ring. Liu ref. [5] investigated the micro-pits on the bearing surface are conducive to the improvement of lubrication performance. Xiao ref. [5] researched that the surface quality of the bearing will be poor and result in instability during operation after processing cycles of beads exceeds 150 times. The principle of SGT is high-pressure gas generated by the air compressor sprays, the grinding material (mixed by steel beads, abrasive powder, and enhanced liquid in a certain proportion) on the surface of the workpiece. The surface of the steel ball carries abrasive powder and hits the surface of the workpiece at high speed, producing a large amount of plastic deformation on the surface, forming a micro texture that helps lubrica- 
tion and introducing residual compressive stress. During the collision of the abrasive and the workpiece, tribochemical effect reacts between the abrasive fluid and the surface of workpiece. A chemically strengthened layer is formed on the surface of the workpiece finally.

The surface strengthening methods of metal materials such as arc ion plating and laser cladding depend on the difficulty of combining the coating with the substrate, and have a certain degree of technicality and high costs. But the strengthening grinding process is simple to operate; the experimental conditions are easy to obtain; it also can obtain greater residual compressive stress than shot peening.

The object of this paper is comparing the running reliabilities of NU308 bearing rings subjected to the SGT and the conventional treatment (CT). CT means grinding and polishing after conventional heat treatment. Then, the running temperature, the vibration, and the surface burning of bearing rings in life tests were experimentally investigated and compared. The residual stress, the surface and cross-section microtopography were further comparatively analyzed. Finally, SGT was proved to be an effective manufacturing method for improving the running reliability of the bearing ring.

\section{Experiments}

\section{Material and processing}

The bearing rings of NU308 with a diameter of $50 \mathrm{~mm}$ and a width of $20 \mathrm{~mm}$, which were manufactured by Suzhou Bearing Factory, were conducted in this study. The bearing ring with heat-treated and finished turning was known as CT sample. The properties of bearing ring were shown in Table 1.

A three-phase mixed jet composed of steel beads, abrasive powder, enhanced liquid, and compressed gas was prepared. G10 bearing steel beads with a particle

size of $1 \mathrm{~mm}$ were selected. The material properties of steel beads were shown in Table 2.

Table 1. The material properties of NU308 bearing ring.

\begin{tabular}{|c|c|c|c|c|c|c|c|c|c|c|}
\hline & \multicolumn{4}{|c|}{ Properties } & \multicolumn{6}{|c|}{ Elements (wt\%) } \\
\hline & $\begin{array}{l}\text { Hardness } \\
\text { (HRC) }\end{array}$ & $\mathrm{Ra}(\mu \mathrm{m})$ & $\begin{array}{c}\text { Yield } \\
\text { limit (MP) }\end{array}$ & $\begin{array}{c}\text { Young's } \\
\text { modulus (GPa) }\end{array}$ & Gr & $\mathrm{C}$ & $\mathrm{Mn}$ & $\mathrm{Si}$ & $\mathrm{O}$ & $\mathrm{Fe}$ \\
\hline Values & $61.0-61.5$ & $0.06-0.08$ & 1744 & 217 & $1.72-1.76$ & $0.93-1.00$ & $0.2-0.3$ & $0.03-0.07$ & $3.99-4.13$ & Bal. \\
\hline
\end{tabular}

Table 2. The material properties of G10 bearing steel beads.

\begin{tabular}{|c|c|c|c|c|c|c|c|c|c|c|}
\hline & \multicolumn{4}{|c|}{ Properties } & \multicolumn{6}{|c|}{ Elements (wt\%) } \\
\hline & $\begin{array}{c}\text { Hardnes } \\
\text { (HRC) }\end{array}$ & $\mathrm{Ra}(\mu \mathrm{m})$ & $\begin{array}{l}\text { Yield limit } \\
(\mathrm{MPa})\end{array}$ & $\begin{array}{c}\text { Young's } \\
\text { modulus (GPa) }\end{array}$ & $\mathrm{Gr}$ & $\mathrm{C}$ & $\mathrm{Mn}$ & $\mathrm{Si}$ & $\mathrm{O}$ & $\mathrm{Fe}$ \\
\hline Values & $63-64.5$ & $0.08-0.10$ & 1844 & 220 & $1.50-1.55$ & $1.05-1.55$ & $0.3-0.41$ & $0.03-0.07$ & $4.23-4.42$ & Bal. \\
\hline
\end{tabular}


Alumina powder having an average Vickers hardness of $2.2 \times 10^{5} \mathrm{MPa}$ and a particle size of 80 mesh was used as the abrasive powder. And the enhanced liquid that consisted of extreme pressure additives, permeating agent, $\mathrm{pH}$ regulator, non-ion surfactant, $\mathrm{pH}$ buffer, preservative, Sodium hydroxide, softener, defoamer, rust inhibitor, and water were prepared with the details shown in Table 3. Finally, a three-phase mixed jet composed of $10 \mathrm{~kg}$ of steel beads, $250 \mathrm{~g}$ of abrasive powder, $200 \mathrm{ml}$ of enhanced liquid, and compressed air were prepared.

The raceway of the bearing ring was subjected to SGT at ambient temperature with the following parameters: $0.7 \mathrm{MPa}$ jet pressure, stand-off distance of 50 $\mathrm{mm}$, inclination angle of $45^{\circ}$, rotating velocity of $100 \mathrm{r} / \mathrm{min}$ and duration of 4 minutes. Figure 1 shows the procedure of the SGT setup.

\section{Dynamic stability characterization}

The samples were assembled to the NU308 bearing, respectively. Except for the bearing ring, the two sets of bearing had identical technical parameters. Then the dynamic stability of NU308 bearings were tested by ABLT-1A bearing fatigue testing machine, which were made in Jinan Yino Century Test Instruments Co. Ltd, with the parameters shown in Table 4. During the test, the bearings were well lubricated with FV68H oil produced by Idemitsu Lube (China) Co. Ltd. The radial vibration and operating temperature of the bearings were recorded every 15 seconds.

Table 3. Component details for the enhanced liquid of SGT.

\begin{tabular}{cc}
\hline Composition & Weight (\%) \\
\hline Fatty acid imidazoline boric acid ester & 20 \\
Dodecyl sodium sulfate & 12 \\
Triethanolamine & 5 \\
Alkyl polyoxyethylene ether & 5 \\
Sodium borate & 4 \\
Calcium benzoate & 2 \\
Caustic soda & 1 \\
Edta disodium & 0.5 \\
Benzotriazole & 0.4 \\
Solydimethyl siloxane & 0.1 \\
Water & 50 \\
\hline
\end{tabular}

Table 4. The component processing parameters of SGT.

\begin{tabular}{cc}
\hline Component parameters & Value \\
\hline Jet pressure $(\mathrm{MPa})$ & 0.7 \\
Stand-off distance $(\mathrm{mm})$ & 50 \\
Inclination angle $\left(^{\circ}\right)$ & 45 \\
Rotating velocity $(\mathrm{r} / \mathrm{min})$ & 100 \\
Duration $(\mathrm{min})$ & 4 \\
\hline
\end{tabular}




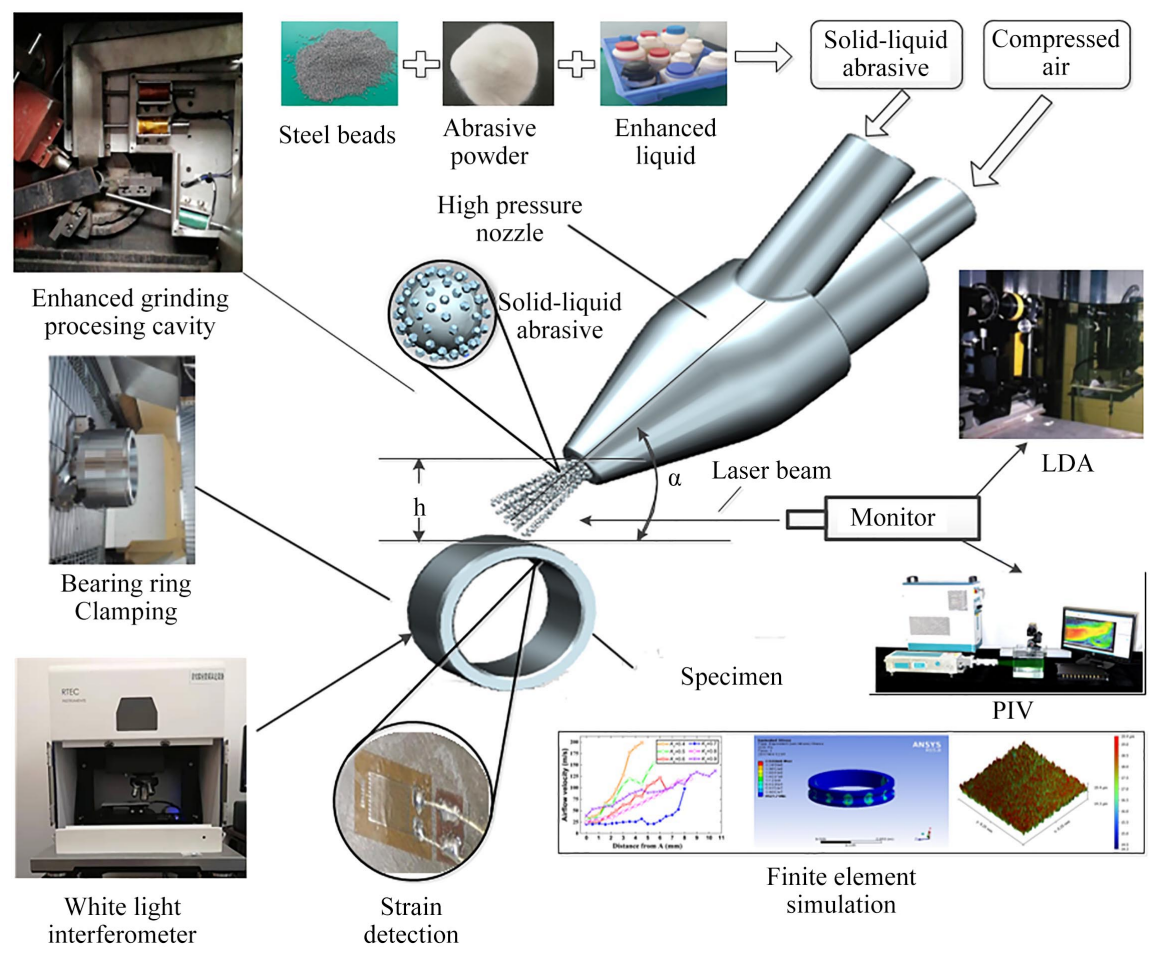

Figure 1. A schematic illustration of the SGT setup.

\section{Residual Stress and Micro-topography Characterization}

The residual stress of CT and SGT samples at different depths from the surface were measured by XRD residual stress analyzer and electrolytic stripping method. The residual stress was measured in two directions: the circumferential direction and the axial direction, as shown in Figure 2. From the surface to the substrate, the residual stress was measured every $15 \mu \mathrm{m}$ intervals. Finally, 12 layers were corroded and 13 sets of residual stress data were obtained. Thereafter, two small blocks with $5 \mathrm{~mm}$ both in length, width and height were cut out from the CT and SGT specimen by wire cut electric discharge machine, respectively. And the microtopography of the treated surface and cross-section of the CT and the SGT specimens were measured by JSM-7001F field-emission scanning electron microscopy.

\section{Results and Discussion}

\section{Dynamic stability experiment results}

Figure 3 shows the running temperature variation of NU308 bearings, which were subjected to CT and SGT, during the dynamic stability tests. The running temperature of the SGT sample increases immediately, from $30.1^{\circ} \mathrm{C}$ to $90.7^{\circ} \mathrm{C}$ in the first 4 hours, and approximately goes down to $85^{\circ} \mathrm{C}$ in the next 6 hours. Then, it rises or drops in the last 55 hours. And it tends to a state between $82^{\circ} \mathrm{C}$ and $84^{\circ} \mathrm{C}$ after testing for 40 hours. The CT sample shows a similar temperature variation trend: Firstly, it rises from $30.1^{\circ} \mathrm{C}$ to $99.9^{\circ} \mathrm{C}$ in the first 4 hours. Then it tends to stabilize around $98^{\circ} \mathrm{C}$ over the next 20 hours and fluctuates between 


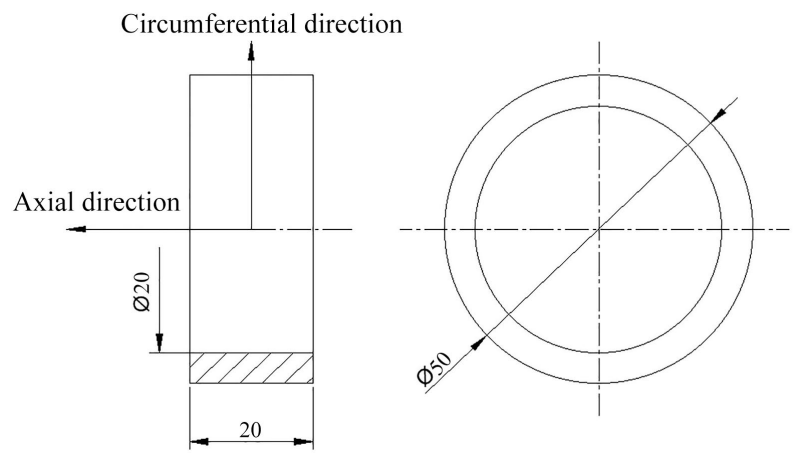

Figure 2. Dimensions of specimen and directions of residual stress measurement.

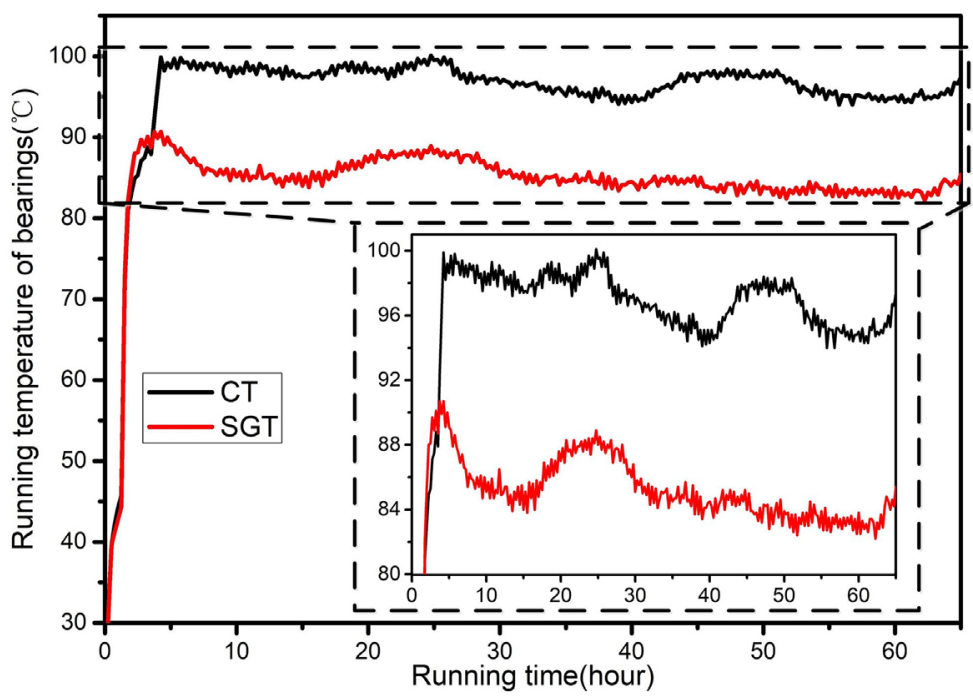

Figure 3. Variation of running temperature for the CT and SGT samples during the dynamic stability test under a dynamic equivalent radial load of $8 \mathrm{KN}$, a spindle speed of $500 \mathrm{r} / \mathrm{min}$, and a test time of 65 hours.

$95^{\circ} \mathrm{C}$ and $99^{\circ} \mathrm{C}$ during the last 41 hours. Furthermore, it can be seen that the running temperature of the SGT sample is lower than that of the CT sample in the last 60 hours, and the maximum difference reaches about $16^{\circ} \mathrm{C}$. The fluctuations of temperature during the test are likely related to different frictional wear, which is considered to be one of the most influential factors for running temperature ref. [13]. According to Ahmadi and Huang ref. [14] [15], the fact that the running temperature of the CT sample is higher than that of the SGT sample, which probably due to the anti-friction performance of the CT sample is worse than that of SGT sample. In other words, the SGT sample has a better ability to control the running temperature than the CT sample.

To further comparing the running performance of the CT and SGT samples, the vibration of bearings was tested, as shown in Figure 4. It can be seen that the CT and SGT specimens have a similar variation trend of vibration during the test, and the vibration range of the CT sample is wider than that of SGT. Furthermore, the vibration of SGT sample is about 0.00 to $0.10 \mathrm{~mm} / \mathrm{s}$ during the 
running time of the 5th hour to the 20th hour and the last 40 hours, while the vibration of CT sample reaches about 0.00 to $0.15 \mathrm{~mm} / \mathrm{s}$ during the 5th hour to the 20th hour, -0.05 to $0.40 \mathrm{~mm} / \mathrm{s}$ between the 20th hour and the 55th hour, and -0.15 to $0.15 \mathrm{~mm} / \mathrm{s}$ in the last five hours. More than that, both the amplitude of CT and SGT samples during about the 22th to 25th hour is greater than that of the first 22 hours. This is most likely leading to further increasing of bearings' friction-wear ref. [16] [17]. Owing to different degrees of wear during the test, the bearing's amplitudes will fluctuate within a certain range. Therefore, it can be speculated that the change of amplitude is probably due to the new wear state of bearing during this period. Overall, the amplitude range of the SGT sample is smaller than that of the CT sample. In other words, the SGT sample has better anti-vibration performance, which plays an important role in the reduction of frictional wear and running temperature.

Figure 5 shows an overview burning situation of the CT and SGT samples before and after the dynamic stability test. The surface burnings of the CT sample is significant, while the SGT sample just has minor burning. And it can be inferred from the results above that the surface burning on the bearing ring is closely related to the running temperature and amplitude. Moreover, it is well known that the burning on the machine part surface are affected by many physical properties, such as friction, wear, lubrication, micro-morphology, residual stress and so on. Interestingly, burnings on the smooth surface were much more serious than on the microporous surfaces according to the test results. Therefore, it can be deduced that the microporous surface has better wear resistance than that of the smooth superfine surface.

\section{Residual stress and hardness}

In order to find out the causes of the differences in running temperature, vibration and surface burning, the residual stress of the CT and SGT samples had been investigated, as shown in Figure 6. The absolute values of the transverse and tangential residual stress of the CT sample were greater than that of SGT sample. And the absolute value of residual compressive stress of the SGT sample rapidly decreased from about $900 \mathrm{MPa}$ to $150 \mathrm{MPa}$ from the surface to $30 \mu \mathrm{m}$ in-depth, while the CT sample decreased from about $500 \mathrm{MPa}$ to zero. Moreover, the residual compressive stress layer's thickness of the CT sample was less than $45 \mu \mathrm{m}$, but the thickness on SGT sample was over $180 \mu \mathrm{m}$. It was reported that the short fatigue crack could be decreased and the fatigue life could be enhanced significantly by incorporating high residual compressive stress ref. [18] [19]. Accordingly, the residual compressive stress layer can effectively improve the anti-fatigue and wear-resistant properties of the workpiece ref. [20] [21] [22]. According to the results above, the absolute value of the residual compressive stress and depth of residual compressive stress layer of the SGT sample are greater than the CT sample. Therefore, the specimen treated with SGT has better wear resistance than the CT specimen. The explanation has a great agreement to the test results above. 


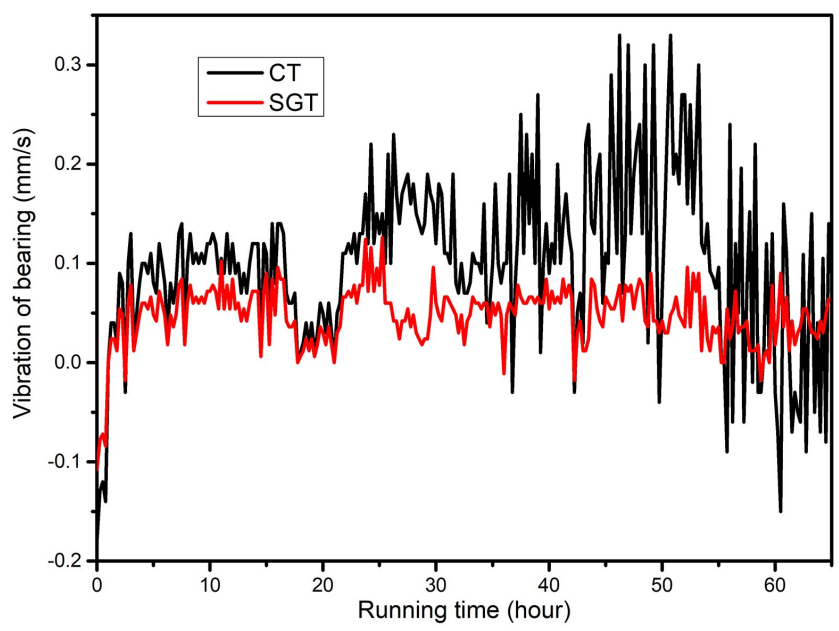

Figure 4. Vibration of CT and SGT specimens during the test under a dynamic equivalent radial load of $8 \mathrm{KN}$, a spindle speed of 500 $\mathrm{r} / \mathrm{min}$, and a test time of 65 hours.
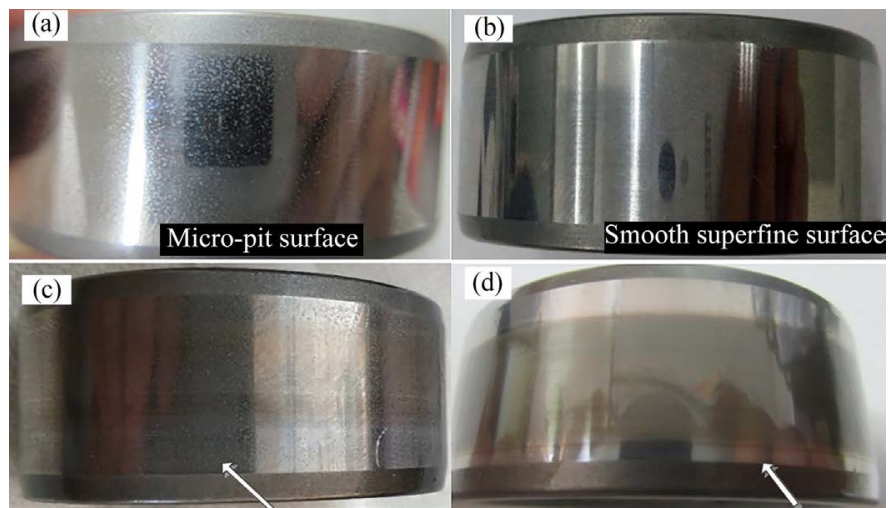

Figure 5. Burning situation of bearing ring: (a) SGT sample with the micro-pit surface before the test; (b) CT sample with the smooth superfine surface before the test; (c) SGT sample with minor burnings after test; (d) CT sample with severe burnings after the test.

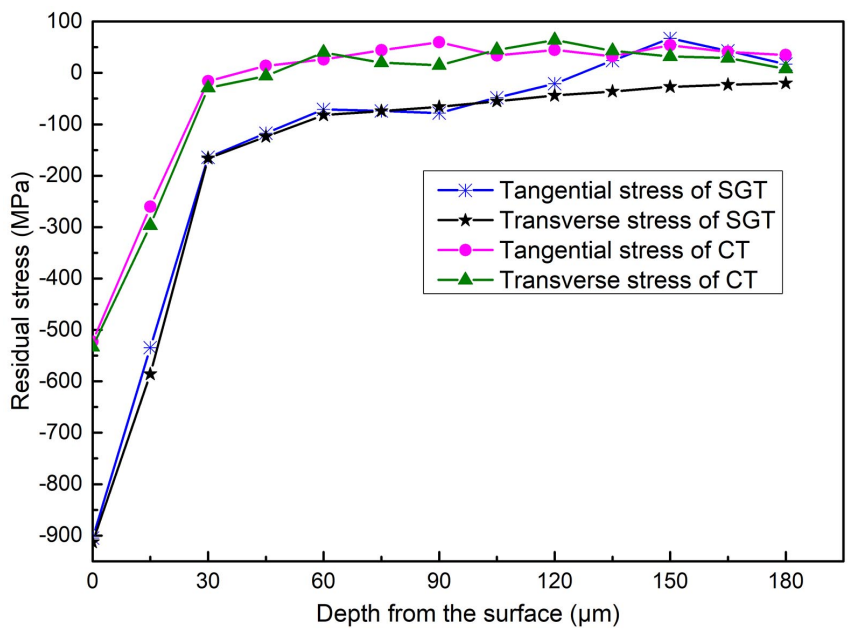

Figure 6. Distribution of circumferential and axial residual stress of CT and SGT samples along the depth. 
The Vickers hardness distribution from the treated surface to the substrate of the CT and SGT samples were also compared. As shown in Figure 7, with the increase of the depth from the treated surface, the hardness of the CT sample fluctuates between $780-800 \mathrm{HV}$, while the SGT sample decreases linearly from 886 $\mathrm{HV}$ to $790 \mathrm{HV}$. Furthermore, when the depth from the surface is less than 110 $\mu \mathrm{m}$, the hardness of the SGT sample is higher than that of the CT sample. Thus, it can be seen that the SGT sample has formed a high hardness surface with gradient variation, which is probably benefit for abrasion-resistance ref. [23] [24].

\section{Microtopography analysis}

In addition to the residual stress, microtopography is also believed to be closely related to the anti-fatigue and wear-resistant properties of the workpiece. Hence, the CT and SGT specimen's microtopography had been studied. The regular strip textures can be seen on the CT specimen's smooth surface shown in Figure 8(a), while disordered microtopography with micropores is found on the rough surface of the SGT sample shown in Figure $8(\mathrm{~b})$. Moreover, the maximum peak-to-valley value of the three-dimensional microtopography of the SGT sample is twice that of the CT sample, as shown in Figure 8(c) and Figure 8(d). Compared with the smooth and regular surface, the rough and irregular surface is more conducive to increase the film thickness according to Zapletal and Guegan et al. ref. [25] [26]. Furthermore, it's reported that the effects of rough and irregular surfaces on friction-resistant capacity become more pronounced than that of the smooth surface under cyclic loading and oil lubrication ref. [27] [28] [29]. Therefore, the SGT sample may create better lubrication condition, which is good for friction reduction and leading to better running stability. The lower running temperature, smaller vibration amplitude, and fewer burning are likely related to the disordered microtopography surface of the SGT sample.

Compared with the CT sample, grain refinement and dislocation enhancement, which contributes to the forming of residual compressive stress and shows the identified mechanically stable of wear resistance and capable of suppressing strain localization ref. [30] [31], are found on the metallographic image on cross-section of SGT sample, as shown in Figure 9. And thickness of severe plastic deformation layer of SGT sample in the cross-sectional metallographic image reaches $50 \mu \mathrm{m}$, while the thickness of plastic deformation layer of the CT sample is nearly zero. Furthermore, the fatigue strength is believed to be improved by inducing recrystallized microstructures ref. [32] [33] [34]. Hence, the STG sample has better friction-resistance performance, which will make the running stability higher, and the vibration amplitude and running temperature lower than that of the CT sample. And the explanation is completely agreed with the test results above.

According to the data obtained by the White Light Interferometer, the micromorphology of the CT and SGT samples were fitted, as shown in Figure 10(a) and Figure 10(b). Additionally, so as to match the surface morphology of bearing rings after ultra-finishing, the fitted surfaces were removed by $5 \mu \mathrm{m}$, as 
shown in Figure 10(c) and Figure 10(d). Then, load capacities of the CAD model were compared.

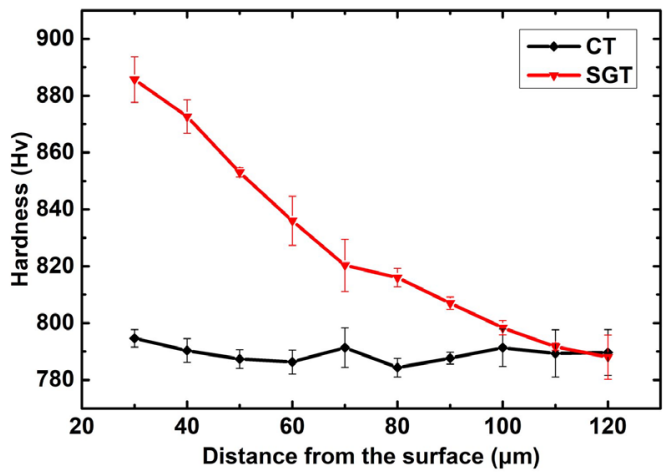

Figure 7. Hardness distribution of CT and SGT samples.
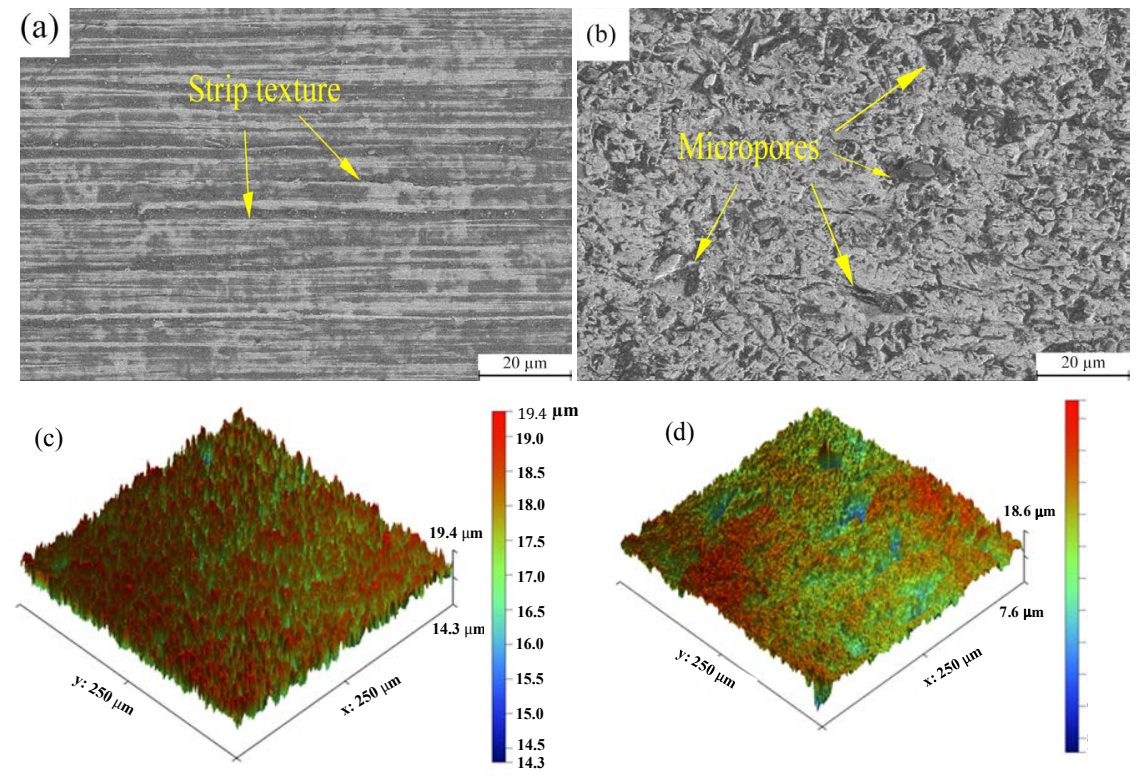

Figure 8. Overview surface microstructure obtained by different treatment: (a) The CT sample with strip texture; (b) The SGT sample with micropores; (c) Three-dimensional topography of CT sample; (d) Three-dimensional topography of SGT sample.
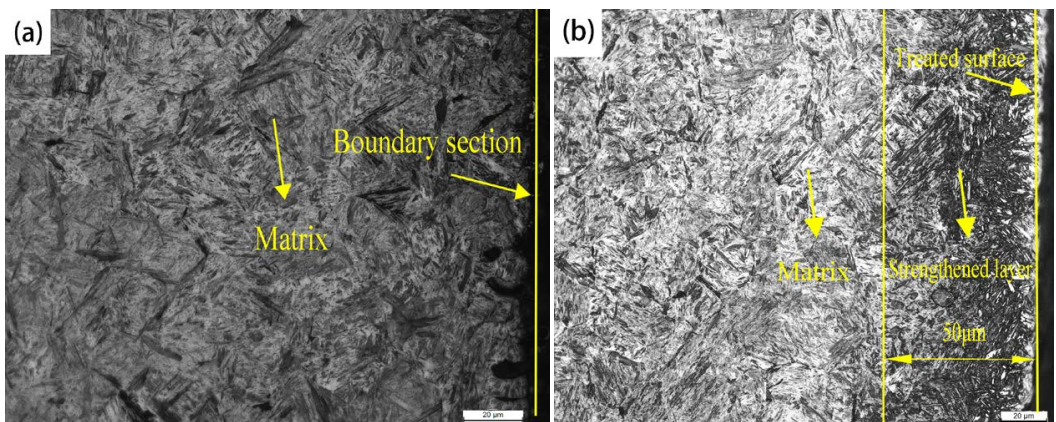

Figure 9. Overview cross-sectional SEM images obtained by different processing technology: (a) The CT sample without strengthen layer; (b) The SGT sample with strengthen layer. 

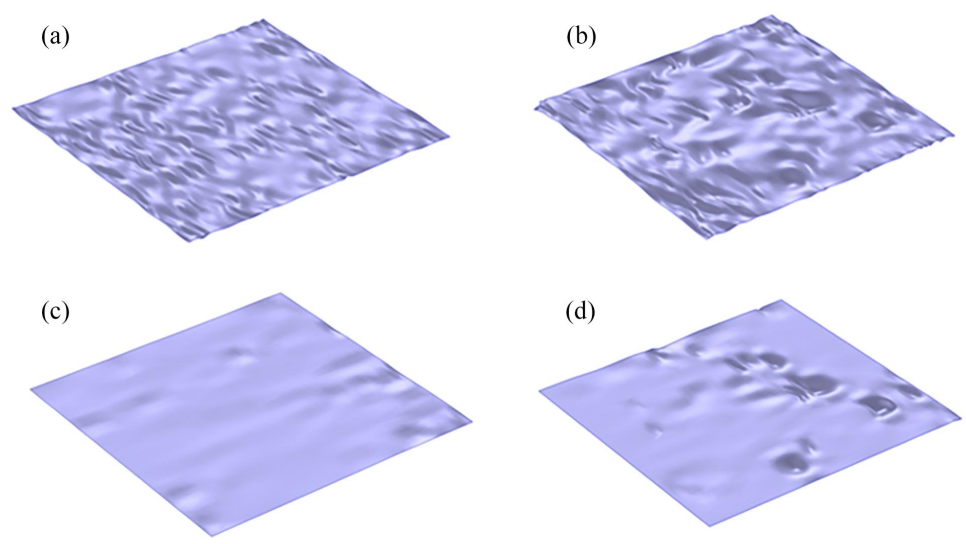

Figure 10. CAD model of fitted surface: (a) CT sample without superfinishing; (b) SGT sample without superfinishing; (c) CT sample superfinished with $5 \mu \mathrm{m}$; (d) SGT sample superfinished with $5 \mu \mathrm{m}$.

It can be know from Figure 11 that the maximum oil film pressure on CT sample was greater than that of SGT sample before and after superfinishing, and the maximum oil film pressure of CT and SGT samples before and after superfinishing are $1.78 \times 10^{6} \mathrm{~Pa}, 7.32 \times 10^{6} \mathrm{~Pa}$, and $6.17 \times 10^{5} \mathrm{~Pa}, 7.26 \times 10^{6} \mathrm{~Pa}$, respectively.

But maximum oil film pressure cannot reflect the load capacity of a fitted surface. Therefore, oil film pressure distribution cloud maps in Figure 11 were subdivided into 3406 oil film pressure values, and 3406 oil film pressure values in each oil film pressure distribution cloud map were summed. It is obtained that the pressure of the oil film unit area $(250 \mu \mathrm{m} \times 250 \mu \mathrm{m})$ on the fitted surface microstructure of the CT and SGT samples before superfinishing is $1.8157 \times 10^{9}$ $\mathrm{Pa}$ and $5.4621 \times 10^{8} \mathrm{~Pa}$. In similar, the pressure of the oil film unit area on the fitted surface microstructure of the CT and SGT samples with super-finished is $8.7451 \times 10^{9} \mathrm{~Pa}$ and $9.915 \times 10^{9} \mathrm{~Pa}$. And the calculation results are shown in Figure 12. The load capacity of the CT and SGT samples before and after superfinishing is $113.48,546.57 \mathrm{~N}$ and $34.14 \mathrm{~N}, 619.69 \mathrm{~N}$, respectively. It is concluded that the CT sample has a better load capacity unit area than the SGT sample before super-finishing. However, the load capacity unit area of the SGT sample exceeds the CT sample after superfinishing with $5 \mathrm{~mm}$. In other words, proper superfinishing after SGT is beneficial to improve the oil film load capacity.

\section{Conclusions}

In this work, the effect of SGT on running reliabilities of NU308 bearing rings is investigated, and the effect mechanisms are comparatively analyzed. Conclusions are drawn as followings.

The running reliabilities of the NU308 bearing ring are improved by SGT when the test was conducted at room temperature. And the surface burning resistance properties induced by SGT are significantly boosted as the application time increases than the untreated samples. The running temperature and vibration of the SGT sample are lower than that of the CT sample. 


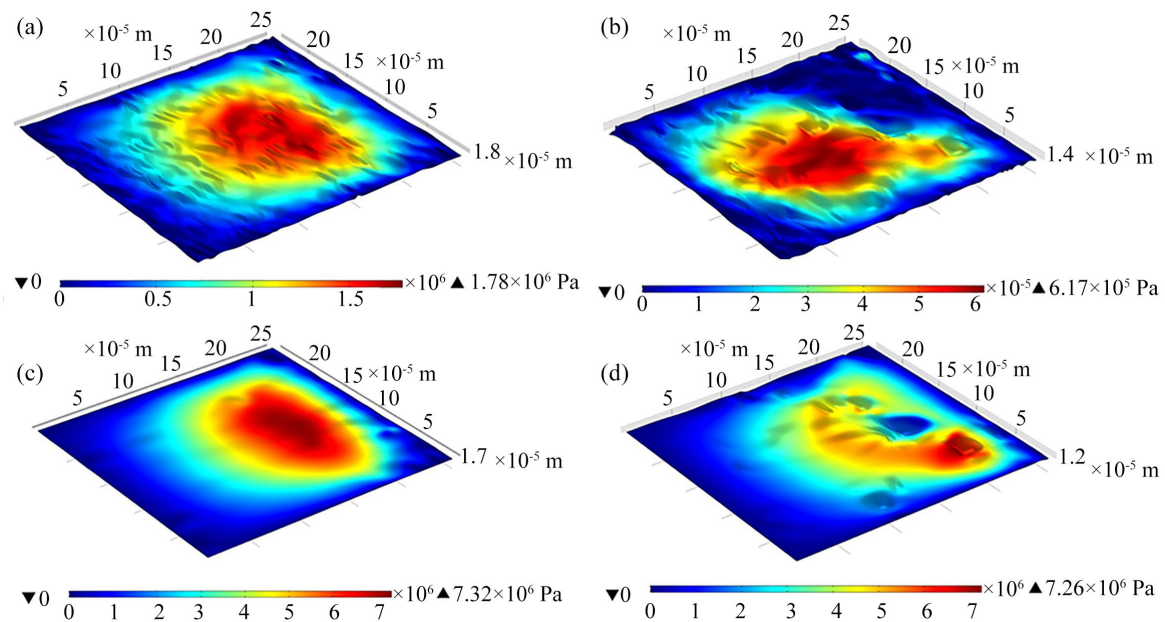

Figure 11. Pressure cloud map of oil film: (a) CT sample without superfinishing; (b) SGT sample without superfinishing; (c) CT sample superfinished with $5 \mu \mathrm{m}$; (d) SGT sample superfinished with $5 \mu \mathrm{m}$.

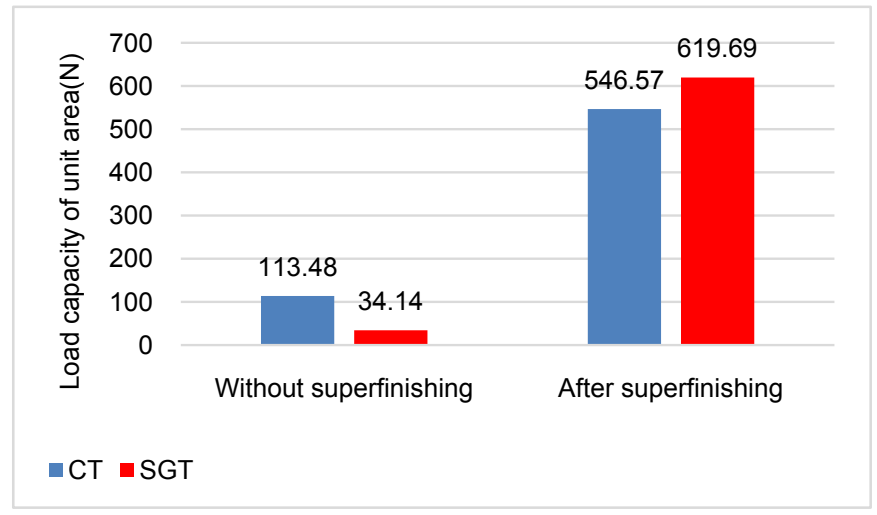

Figure 12. Unit area $(250 \mu \mathrm{m} \times 250 \mu \mathrm{m})$ load capacity of the CT and SGT samples.

The thickness of residual compressive stress layer of the SGT sample is over $180 \mu \mathrm{m}$, while the CT sample is less than $45 \mu \mathrm{m}$. And the maximum residual compressive stress of the SGT sample reaches approximately -900 MPa, while CT sample is only about -500 MPa. It is concluded SGT induced residual compressive stress by a large of plastic deformation. The greater residual compressive stress on the surface of the material, the less likely to form fatigue defects on the surface, so the sample's ability to resist friction and wear is greater. Hence, the SGT sample shows better wear resistance property.

The surface of the SGT sample is covered with disordered micropores that help store oil, while the CT sample is filled with regular textures. These micropores improve the frictional performance of bearing ring ref. [11]. This is why running temperature and vibration of SGT sample is lower than that of CT sample. And the thickness of severe plastic deformation layer of the SGT sample is about $50 \mu \mathrm{m}$, while no significant plastic deformation can be found in the CT sample. 
In a word, SGT is an effective manufacturing method to reduce the running temperature, vibration and surface burning of bearing ring by introducing high residual compressive stress, disordered micropores, and plastic deformation. The SGT improves the reliability of the bearing and lays the foundation for the subsequent research on the influence of enhanced grinding on the wear resistance of bearing rings.

\section{Acknowledgements}

This research was supported by the National Natural Science Foundation of China (Grant U1601204, 51975136), National Key R\&D Program (2018YFB2000501-03), Guangdong Province Key Field R\&D Program (2019B090917004), Guangdong Science and Technology Plan (2016A010102022, 2017A010102014), The Science and Technology Planning Project of Guangdong China (2019B020404), Special projects in key areas of universities and colleges in Guangdong Province (2019KZDZX1009), Science and Technology Innovation Team Project of Colleges and Universities in Guangdong Province (2017KCXTD025), Guangzhou Education System Innovation Academic Team Project (1201610013), 2019 "Fundamental Innovation" Project of Full-time Graduate Students of Guangzhou University (2019GDJC-M21).

\section{Conflicts of Interest}

The authors declare no conflicts of interest regarding the publication of this paper.

\section{References}

[1] Schuhler, G., Jourani, A., Bouvier, S. and Perrochat, J.M. (2018) Efficacy of Coatings and Thermochemical Treatments to Improve Wear Resistance of Axial Piston Pumps. Tribology International, 126, 376-385. https://doi.org/10.1016/j.triboint.2018.05.007

[2] Gheisari, R. and Polycarpou, A.A. (2018) Three-Body Abrasive Wear of Hard Coatings: Effects of Hardness and Roughness. Thin Solid Films, 666, 66-75. https://doi.org/10.1016/j.tsf.2018.07.052

[3] Trdan, U, Skarba, M, Porro, J.A., Ocaña, J.L. and Grum, J. (2018) Application of Massive Laser Shock Processing for Improvement of Mechanical and Tribological Properties. Surface \& Coatings Technology, 342, 1-11. https://doi.org/10.1016/j.surfcoat.2018.02.084

[4] Wang, X., Xia, W.G., Wu, X.Q., Wei, Y.P. and Huang, C.G. (2013) Microstructure and Mechanical Properties of an Austenite NiTi Shape Memory Alloy Treated with Laser Induced Shock. Materials Science and Engineering: A, 578, 1-5. https://doi.org/10.1016/j.msea.2013.04.058

[5] Spadaro, L., Hereñú, S., Strubbia, R., Gómez Rosas, G., Bolmaro, R. and Rubio González, C. (2020) Effects of Laser Shock Processing and Shot Peening on 253 MA Austenitic Stainless Steel and Their Consequences on Fatigue Properties. Optics \& Laser Technology, 122, Article ID: 105892. https://doi.org/10.1016/j.optlastec.2019.105892 
[6] Wang, C., Shen, X.J., An, Z.B., Zhou, L.C. and Chai, Y. (2016) Effects of Laser Shock Processing on Microstructure and Mechanical Properties of K403 Nickel-Alloy. Materials \& Design, 89, 582-588. https://doi.org/10.1016/j.matdes.2015.10.022

[7] Zhao, X.H., Zhou, H.Y. and Liu, Y. (2018) Effect of Shot Peening on the Fatigue Properties of Nickel-Based Superalloy GH4169 at High Temperature. Results in Physics, 11, 452-460. https://doi.org/10.1016/j.rinp.2018.09.047

[8] Klotz, T., Delbergue, D., Bocher, P., Lévesque, M. and Brochu, M. (2018) Surface Characteristics and Fatigue Behavior of Shot Peened Inconel 718. International Journal of Fatigue, 110, 10-21. https://doi.org/10.1016/j.ijfatigue.2018.01.005

[9] Mutter, M., Mauer, G., Mücke, R., Guillon, O. and Vaßen, R. (2017) Correlation of Splat Morphologies with Porosity and Residual Stress in Plasma-Sprayed YSZ Coatings. Surface \& Coatings Technology, 318, 157-169. https://doi.org/10.1016/j.surfcoat.2016.12.061

[10] Huang, S., Zhou, J.Z., Du, J.J., Sun, Y.Q. and Li, M.X. (2008) Visual Study on Surface Micro-Topography and Residual Stress of Sheet Metal after Pulsed Laser Peening. Key Engineering Materials, 3, 334-337. https://doi.org/10.4028/www.scientific.net/KEM.373-374.334

[11] Liu, X.C., Xie, X.C., Zhang, C., et al. (2019) Effect of Micro-Dimples on Bearing Friction Performance in Strengthen Grinding. Tool Technology, 53, 28-30. (In Chinese)

[12] Xiao, J.R., Liu, X.C., Liang, Z.W., et al. (2018) Effect of Steel Bead's Damage on the Surface Roughness and Hardness of Bearing Rings under Strengthen Grinding Processing. Surface Technology, 47, 290-295.

[13] Fu, L.H., Han, W., Zhao, L., Gong, K., et al. (2018) Effects of $\mathrm{Cr}_{3} \mathrm{C}_{2}$ Content and Temperature on Sliding Friction and Wear Behaviors of $\mathrm{Cr}_{3} \mathrm{C}_{2} / \mathrm{Ni}_{3} \mathrm{Al}$ Composite Materials. Wear, 11, 163-173. https://doi.org/10.1016/j.wear.2018.08.013

[14] Ahmadi, A., Sadeghi, F. and Shaffer, S. (2018) In-Situ Friction and Fretting Wear Measurements of Inconel 617 at Elevated Temperatures. Wear, 9, 110-118. https://doi.org/10.1016/j.wear.2018.06.007

[15] Huang, Y.T., Zhou, X.L., Hua, N.B., Que, W.M. and Chen, W.Z. (2018) High Temperature Friction and Wear Behavior of Tungsten-Copper Alloys. International Journal of Refractory Metals and Hard Materials, 77, 105-112. https://doi.org/10.1016/j.ijrmhm.2018.08.001

[16] Mo, J.L., Wang, Z.G. and Chen, G.X. (2013) The Effect of Groove-Textured Surface on Friction and Wear and Friction-Induced Vibration and Noise. Wear, 301, 671-681. https://doi.org/10.1016/j.wear.2013.01.082

[17] Wang, H.J., Liu, Z.L., Zou, L. and Yang, J. (2017) Influence of Both Friction and Wear on the Vibration of Marine Water Lubricated Rubber Bearing. Wear, 4, 920-930. https://doi.org/10.1016/j.wear.2017.02.006

[18] Li, H.Y., Sun, H.L., Bowen, P. and Knott, J.F (2018) Effects of Compressive Residual Stress on Short Fatigue Crack Growth in a Nickel-Based Superalloy. International Journal of Fatigue, 108, 53-61. https://doi.org/10.1016/j.ijfatigue.2017.11.010

[19] Choi, Y. (2009) A Study on the Effects of Machining-Induced Residual Stress on Rolling Contact Fatigue. International Journal of Fatigue, 31, 1517-1523. https://doi.org/10.1016/j.ijfatigue.2009.05.001

[20] Ding, K.Y., Guo, Y.F. and Zou, H. (2017) Effect of Residual Stress on Bending Fatigue Behavior of Inconel 718 Coated with WC-17Co. Rare Metal Materials and Engineering, 46, 307-311. https://doi.org/10.1016/S1875-5372(17)30085-1 
[21] Valiorgue, F., Zmelty, V., Dumas, M., Chomienne, V., Verdu, C., Lefebvre, F. and Rech, J. (2018) Influence of Residual Stress Profile and Surface Microstructure on Fatigue Life of a 15-5PH. Procedia Engineering, 23, 623-629. https://doi.org/10.1016/j.proeng.2018.02.058

[22] Kattoura, M., Ramaiah, S.M., Qian, D. and Vasudevan, V.K. (2018) Effect of Ultrasonic Nanocrystal Surface Modification on Elevated Temperature Residual Stress, Microstructure, and Fatigue Behavior of ATI 718Plus Alloy. International Journal of Fatigue, 110, 186-196. https://doi.org/10.1016/j.ijfatigue.2018.01.017

[23] Mellouli, D., Haddar, N., Köster, A. and Ayedi, H.F. (2014) Hardness Effect on Thermal Fatigue Damage of Hot-Working Tool Steel. Engineering Failure Analysis, 45, 85-95. https://doi.org/10.1016/j.engfailanal.2014.06.007

[24] Vrcek, A., Hultqvist, T., Baubet, Y., Björling, M., Marklund, P. And Larsson, R. (2018) Micro-Pitting and Wear Assessment of Engine Oils Operating under Boundary Lubrication Conditions. Tribology International, 129, 338-346. https://doi.org/10.1016/j.triboint.2018.08.032

[25] Zapletal, T., Sperka, P., Krupka, I. and Hartl, M. (2018) the Effect of Surface Roughness on Friction and Film Thickness in Transition from EHL to Mixed Lubrication. Tribology International, 128, 237-243.

https://doi.org/10.1016/j.triboint.2018.07.047

[26] Guegan J, Kadiric A, Gabelli A and Spikes H (2016) the Relationship between Friction and Film Thickness in EHD Point Contacts in the Presence of Longitudinal Roughness. Tribology Letters, 64, Article No. 33. https://doi.org/10.1007/s11249-016-0768-6

[27] Liu, D.R., Yan, B., Shen, B., Liu, L. and Hu, W.B. (2018) Friction Behaviors of Rough Chromium Surfaces under Starving Lubrication Conditions. Applied Surface Science, 427, 857-862.

[28] Fricke, S., Hager, C., Solovyev, S., Wangenheim, M. and Wallaschek, J. (2018) Influence of Surface Form Deviations on Friction in Mixed Lubrication. Tribology International, 118, 491-499. https://doi.org/10.1016/j.triboint.2017.05.032

[29] Volchok, A., Halperin, G. and Etsion, I. (2002) The Effect of Surface Regular Microtopography on Fretting Fatigue Life. Wear, 253, 509-515. https://doi.org/10.1016/S0043-1648(02)00148-5

[30] Chen, X., Han, Z., Li, X.Y. and Lu, K. (2016) Lowering Coefficient of Friction in Cu Alloys with Stable Gradient Nanostructures. Science Advances, 2, e1601942. https://doi.org/10.1126/sciadv.1601942

[31] Zuo, J.R., Hou, L.G., Shi, J.T., Cui, H., Zhuang, L.Z. and Zhang, J.S. (2017) the Mechanism of Grain Refinement and Plasticity Enhancement by an Improved Thermomechanical Treatment of $7055 \mathrm{Al}$ Alloy. Materials Science and Engineering. A, 702, 42-52. https://doi.org/10.1016/j.msea.2017.06.106

[32] Liu, R., Tian, Y.Z., Zhang, Z.J., Zhang, P. and Zhang, Z.F. (2017) Fatigue Strength Plateau Induced by Microstructure Inhomogeneity. Materials Science and Engineering: $A$, 702, 259-264. https://doi.org/10.1016/j.msea.2017.07.026

[33] Shukla, S., Wang, T.H., Cotton, S. and Mishra, R.S. (2018) Hierarchical Microstructure for Improved Fatigue Properties in a Eutectic High Entropy Alloy. Scripta Materialia, 156, 105-109. https://doi.org/10.1016/j.scriptamat.2018.07.022

[34] Wu, P.F., Deng, Y.L., Zhang, J., Fan, S.T. and Zhang, X.M. (2018) The Effect of Inhomogeneous Microstructures on Strength and Fatigue Properties of an Al-Cu-Li Thick Plate. Materials Science and Engineering. A, 731, 1-11.

https://doi.org/10.1016/j.msea.2018.06.033 